\title{
Pembinaan Transformatif Bagi Warga Binaan Di Lembaga Pembinaan Anak Kelas II Batam
}

\author{
Fredy Simanjuntak ${ }^{1}$, Rita Evimalinda ${ }^{2}$, Ardianto Lahagu ${ }^{3}$, Efvi Noyita ${ }^{4}$, Ester Lina \\ Situmorang ${ }^{5}$, Agiana Her Visnhu Ditakristi ${ }^{6}$ \\ 1, Prodi Teologi, STT REAL Batam \\ 2,3,4, 5, 6 Prodi Teologi, STT REAL Batam \\ *fredygrace@gmail.com
}

\begin{abstract}
The "Mental \& Spiritual Development" program was initiated by STT REAL Batam and GBI Windsor House of Glory. This coaching program is a routine program of STT REAL Batam to carry out the threefold missions of higher education, which is the first program/pilot project in collaboration with GBI Windsor Square House of Glory which is committed to the field of Mental \& Spiritual Development of Christian Inmates in Child Correctional Institutions Batam. It is hoped that this coaching program, can support government programs in rehabilitative, corrective, and educative services to the inmates and take part in building the values of life so that they can equip the inmates spiritually so that they can carry out their roles as good and good citizens of society. useful. This coaching program itself is a mentoring movement to improve the quality of piety to God Almighty, intellectual, professional attitudes and behavior, physical and spiritual health of the inmates. Furthermore, coaching is expected so that they are able to improve themselves and do not repeat the crimes that have been committed.
\end{abstract}

Keywords: Transformative Guidance, Fostered Residents, Child Correctional Institution, Batam

\begin{abstract}
Abstrak
Program "Mental \& Spiritual Development" ini digagas oleh STT REAL Batam dan GBI Windsor House of Glory. Program pembinaan ini merupakan program rutin STT REAL Batam untuk mengemban tridharma perguruan tinggi yang merupakan program/pilot project pertama bekerjasama dengan GBI Windsor Square House of Glory yang berkomitmen pada bidang Pembinaan Mental \& Spiritual Narapidana Kristen di Lembaga Pembinaan Anak Kelas II Batam. Diharapkan program pembinaan ini, dapat mendukung program pemerintah dalam pelayanan rehabilitatif, korektif, dan edukatif kepada warga binaan serta ikut membangun nilai-nilai kehidupan sehingga dapat membekali warga binaan secara spiritual agar dapat menjalankan perannya dengan baik. dan warga masyarakat yang baik. berguna. Program pembinaan ini sendiri merupakan gerakan pendampingan untuk meningkatkan kualitas ketakwaan kepada Tuhan Yang Maha Esa, intelektual, sikap dan perilaku profesional, kesehatan jasmani dan rohani warga binaan. Selanjutnya diharapkan pembinaan agar mereka mampu memperbaiki diri dan tidak mengulangi kejahatan yang telah dilakukan Kata kunci: Pembinaan Transformatif, Warga Binaan, Lembaga Pembinaan Anak, Batam
\end{abstract}

\section{PENDAHULUAN}

Menurut observasi penulis ada sekitar 30 anak binaan Kristen yang berhadapan dengan hukum saat ini di lembaga pembinaan khusus anak kelas II Batam. Namun kondisi LPKA juga berdampingan dengan Lembaga pembinaan untuk warga binaan yang yang lebih dewasa. Keberadaan anak-anak dalam tempat penahanan dan pemenjaraan Bersama orang-orang yang lebih dewasa, menempatkan anak-anak pada situasi rawan menjadi korban berbagai tindak kekerasan. ${ }^{1}$ Dapat dibayangkan bagaimana anak alan menjalani masa hukuman di penjara merupakan bentuk konsekuensi pelaku atas perbuatan yang dilakukan. Berada jauh dari dunia luar yang bebas, tentu merupakan hal yang berat, terutama bagi para pelaku kejahatan yang masih berusia di bawah 18 tahun. Masalah kebebasan cukup berat bagi warga binaan, Eric Olin Wright dalam Criminal Justice Al lies and Adversaries mengatakan "kebebasan adalah satu-satunya hal yang berarti bagi manusia tanpa kebebasan hal-hal kehilangan makna. Seluruh sistem penjara dirancang untuk merendahkan manusia, menghancurkannya sebagai

\footnotetext{
${ }^{1}$ Nashriana, Perlindungan Hukum Pidana Bagi Anak Di Indonesia (Jakarta: RajaGrafindo persada, 2012). 159
} 
manusia. Merampas semua kebebasannya untuk mengekspresikan dirinya dan perasaannya. ${ }^{2}$

Adanya model pembinaan bagi warga binaan di dalam Lembaga Pemasyarakatan tidak terlepas dari sebuah dinamika, yang bertujuan untuk lebih banyak memberikan bekal bagi Narapidana baik saat berada di dalam lembaga permasyarakatan maupun dalam menyongsong kehidupan setelah selesai menjalani masa hukuman (bebas). Oleh karena itu, mereka perlu dibekali dengan pembinaan mental dan spiritual yang relevan untuk menghadapi tantangan masa depan. Salah satu pembinaan yang ingin difasilitasi oleh pengabdian masyarakat kali ini adalah tentang transformasi ke arah kristus.

Warga Binaan sebagian besar hidupnya dalam kesusahan dan kekurangan, karena Mereka kehilangan pekerjaan. Keadaan seperti ini sering meruntuhkan sisi spiritual dan mental mereka untuk meneruskan kehidupan selanjutnya. Karena itu kewajiban kita sebagai saudara seiman tentu sangatlah berarti, tidak hanya dengan simpati, tapi perlu adanya tindakan nyata dengan memberikan mereka penyuluhan dan pembinaan tentang Ttransformasi diri. Adalah sangat berdosa bagi kita, apabila kita berdiam diri membiarkan hidup mereka hidup dalam kehidupan lama yang sarat akan dosa.

Dengan diberikannya materi pembinaan mental dan spiritual ini, warga binaan menjadi terbuka dan mampu mengatur dan mengevaluasi sikap, pemikiran dan perasaan mereka sehingga menjadi lebih efektif dan bermanfaat. Perlu adanya dukungan dari pihak Yayasan untuk menjalankan pelatihan ini agar tersampaikan dengan maksimal.

Sebagaimana disadari bahwa pembinaan narapidan di dalam lembaga pemasyarakatan bertujuan antara lain adalah reintegrasi untuk mongembalikan kesatuan hubungan hidup dan kehidupan antara terpidana dengan masyarakat luas melalui pembinaan narapidana yang kolaboratif, yaitu kerjasarna antara petugas terpidana dan masyarakat untuk mengurangi keterasingan (isolasi) terpidana dengan kehidupan masyarakat luas baik dalam arti fisik maupun nilai-nilai masyarakat. ${ }^{3}$

\section{Permasalahan Lapangan}

Pembinaan diadakan di Lembaga Pembinaan Khusus Anak \& Lembaga Permasyarakatan Perempuan Kelas II Batam. Berkenaan dengan masalah petugas pembinaan di Lembaga Pemasyarakatan, ternyata dapat dikatakan belum sepenuhnya dapat menunjang tercapainya tujuan dari pembinaan itu sendiri, mengingat sebagian besar dari mereka relatif belum ditunjang oleh bekal kecakapan melakukan pembinaan dengan pendekatan humanis yang dapat menyentuh perasaan para narapidana, dan mampu berdaya cipta dalam melakukan pembinaan. Lokasi berada di Jl. Jenderal Sudirman Sei Baloi Batam. Hal lain yang diamati oleh penulis adalah lingkungan yang rawan tempat melaksanakan pembinaan bagi para narapidana, sewaktu-waktu bisa justru bisa menjadi salah satu tempat yang sering terjadi kejahatan kekerasan yang dilakukan sesama narapida. ${ }^{4}$ Hal senada juga dinyatakan oleh Adiansyah mengenai Lembaga pemasyarakatan juga menjadi tempat yang berisiko tinggi terhadap perilaku kekerasan fisik, psikologis, dan ekonomi. ${ }^{5}$

\section{Tujuan Kegiatan}

Tujuan pembinaan mental dan spiritual ini adalah untuk:

1. Membantu warga binaan memahami identitas mereka di dalam Kristus

2. Memberikan semangat dan motivasi bagi warga binaan dalam menjalani kehidupannya di lembaga permasyarakatan

3. Membuka paradigma berpikir warga binaan mengalami transformasi hidup yang berkualitas

\section{Manfaat kegiatan}

1. Menyiapkan warga binaan pemasyarakatan agar dapat berintegrasi secara sehat dengan masyarakat

2. Pemulihan kesatuan hubungan warga binaan pemasyarakatan dengan masyarakat.

\footnotetext{
${ }^{2} \mathrm{~J}$ Snortum and I Hadar, Criminal Justice : Allies and Adversaries (New York: Palisades Publishers, 1978). 183

3 Thomas Sunaryo, "Perpustakaan Penjara,” Majalah Bahana (Jakarta, 1983).26

${ }^{4}$ Hevi Selvina, "Peran Lembaga Pemasyarakatan Dalam Penanggulangan Kekerasan Yang Dilakukan Oleh Narapidana," POENALE 5, No. 2 (2017): 1-10.2

5 Adiansyah And Sukihananto, "Kekerasan Fisik Dan Psikologis Pada Narapidana Lansia Di Lembaga Pemasyarakatan Jawa Barat,” Jurnal Keperawatan Indonesia 20, No. 3 (2017): 168-175.
} 
3. Warga binaan pemasyarakatan dapat ikut serta perperan aktif dalam pembangunan serta hidup yang wajar sebagai warga negara yang baik dan bertanggung jawab, hal ini serupa dengan tujuan dari sitem pemasyarakatan yang berlaku di indonesia.

\section{Tahapan Kegiatan}

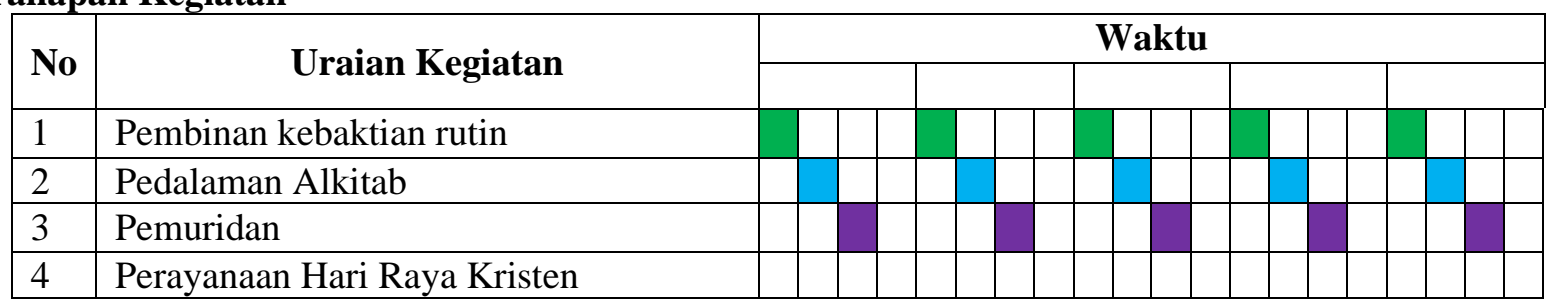

\section{Metode Penelitian}

Metode kegiatan yang digunakan adalah kita mendatangi Lapas Anak \& Perempuan dan akan memberikan pembinaan baik lewat ceramah, bimbingan, persekutuan doa. Hampir seluruh tindak kejahatan yang ditangani oleh Sistem Peradilan Pidana Indonesia selalu berakhir di penjara. Padahal penjara bukan solusi terbaik dalam menyelesaikan masalah-masalah kejahatan, khususnya tindak kejahatan di mana "kerusakan" yang ditimbulkan oleh tindak kejahatan tersebut masih bisa di restorasi sehingga kondisi yang telah "rusak" dapat dikembalikan menuju keadaan semula, di mana dalam keadilan restoratif ini dimungkinkan adanya penghilangan stigma dari individu pelaku. Dalam menyikapi tindak kejahatan yang dianggap dapat direstorasi kembali, dikenal suatu paradigma penghukuman yang disebut sebagai restorative justice, di mana pelaku kejahatan didorong untuk memperbaiki kerugian yang telah ditimbulkannya kepada korban, keluarganya dan juga masyarakat. Berkaitan dengan kejahatan yang kerusakannya masih bisa diperbaiki, pada dasarnya masyarakat menginginkan agar bagi pelaku diberikan "pelayanan" yang bersifat rehabilitatif. Masyarakat mengharapkan para pelaku kejahatan akan menjadi lebih baik dibanding sebelum mereka masuk ke dalam institusi penjara, inilah yang dimaksud proses rehabilitasi.

\section{HASIL DAN PEMBAHASAN}

\section{Gambaran Lokasi Penelitian}

Lembaga Pemasyarakatan Anak atau yang biasa disebut juga dengan Lembaga Pembinaan Khusus Anak Kelas II Batam merupakan hasil alih fungsi bangunan Rumah Tahanan Negara Klas IIA Batam yang terletak di Jln. Jenderal Sudirman No.03 Sei Baloi - Batam. Lembaga Pemasyarakatan Anak Klas III Batam diresmikan pada tanggal 05 Agustus 2015 oleh Kepala Kantor Wilayah Kementerian Hukum dan Hak Asasi Manusia Kepulauan Riau dan Ibu DPRD TK II Batam dan Ka UPT sebatam,yg secara serentak di seluruh Indonesia,menjadi Lembaga Pembinaan Khusus Anak.Lembaga Pembinaan Khusus Anak Klas II Batam memiliki kapasitas 250 (dua ratus lima puluh )orang dengan luas tanah perkantoran $10.361 \mathrm{~m} 2$



Gambar 1. Tampak Depan LPKA Kelas II Batam 


\section{Pembinaan Mental \& Spiritual Warga Binaan}

Pembinaan ini dilakukan bertujuan agar warga binaan pemasyarakatan meneguhkan imannya, terutama iman yang mendekatkan pada Tuhan dan sesama manusia dan mengertikan warga binaan untuk menyadari perbuatan yang telah dilakukannya. Pendekatan agama ini diharapkan dapat menjadi cara yang baik dalam memberikan pengertian kepada warga binaan pemasyarakatan.

Adapun wujud kegiatan pembinaan yang dilaksanakan meliputi: pembinaan kebaktian rutin, pemahaman alkitab, permuridan serta perayaan hari Kristen. Dalam melaksanakan pendidikan kerohanian ini pihak lapas bekerja sama dengan gereja-gereja terdekat dikota magelang seperti mendatangkan pastor dan pendeta

Kegiatan ini dilakukan kurang lebih empat bulan sesuai dengan Perjanjian Mou dengan Pihak Lembaga, dikarenakan ada banyak gereja dan organisasi Kristen yang ambil bagian di dalam Pelayanan kepada warga binaan ini. Kegiatan Pembinaan dilaksanakan dari awal bulan 5 Nopember 2018 hingga akhir 10 Januari tahun 2019. Kebaktian biasanya diadakan setiap minggu pertama setiap bulan, kemudian dilanjutkan dengan kegiatan pedalaman alkitaba di setiap minggu ke dua, pemuridan dilakukan setiap minggu ke tiga dan perayaan hari Raya Kristen disesuaikan dengan waktu dan ketentuan dari pihak Lembaga.



Gambar 2. Kegiatan Pembinaan Rutin Tim PkM ke LPKA Kelas II Batam

Pembinaan diadakan di dalam lapas, sebaimana kita ketahui bahwa para penghuni lapas adalah mereka yang tidak memiliki hak kebebasan oleh karena pelanggaran hukum yang mereka lakukan. Melalui berbagai kegiatan seperti ibadah, pedalaman alkitab dan pemuridan, warga binaan akan memperoleh pengajaran. Dimana pengajaran dalam persekutuan yaitu didasari oleh Injil. Marthin Luther dalam Latif pengajaran agama bertujuan menyadarkan orang akan dosa serta bersukacita oleh firman yang memerdekakan melalui Yesus Kristus. Latif membandingkan pendapat Luther dengan John Calvin dalam pengartina pengajaran agama menurut padangan kedua tokoh besar gereja ini. menurut Calvin pengajaran membawa orang-orang untuk mengabdi kepada Allah Bapa dan Yesus Kristus. ${ }^{6}$

${ }^{6}$ Helen Farida Latif, "Pengaruh Pengajaran Dan Persekutuan Terhadap Tingkat Pertumbuhan Rohani Anak Dan Remaja," EPIGRAPHE 1, No. 1 (2017): 119-138.121 


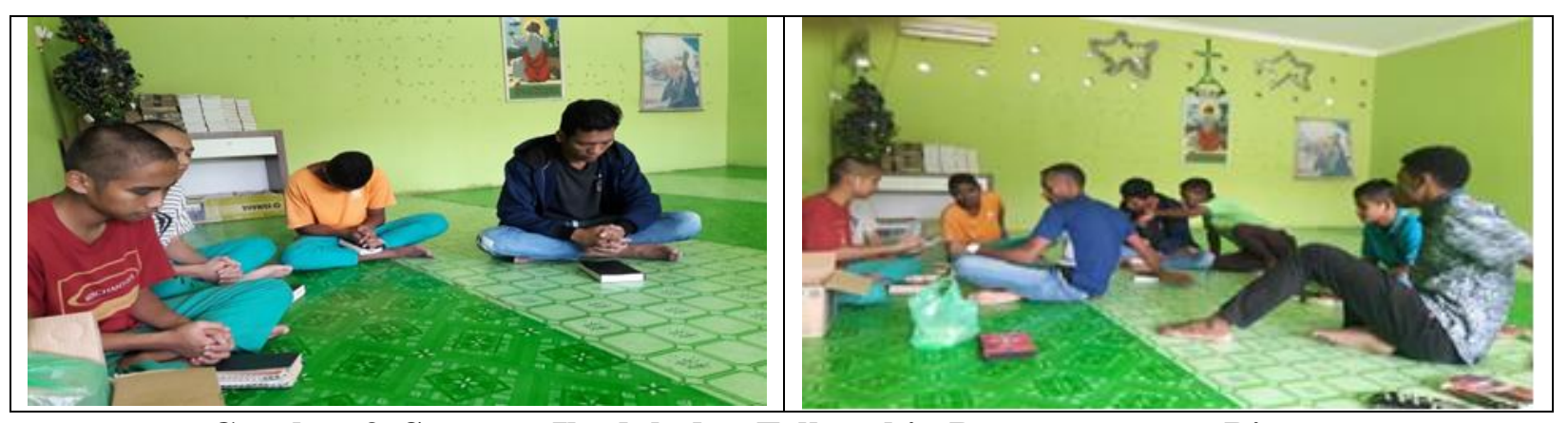

Gambar 3. Suasana Ibadah dan Fellowship Bersama warga Binaan

Pembinaan berupa interaksi langsung yang sifat- nya kekeluargaan antara pembina dengan yang di bina (warga binaan pemasyarakatan). Pada dasarnya seorang warga binaan pemasyarakatan sangat membutuhkan perhatian, khususnya perhatian dari keluarga maupun kerabat terdekat serta orang-orang yang ada disekitar baik itu teman-teman warga binaan pemasyarakatan yang lain maupun petugas lembaga pemasyaraktan yang terjun langsung dalam memberikan pendampingan guna untuk menumbuhkan metalnya agar tidak merasa bahwa mereka orang yang terkucilkan maupun orang yang dianggap sebagai orang yang tidak memiliki masa depan untuk bangsa, negara masyarakat serta lingkungan sekitarnya.Oleh karena itu Pembinaan yang dilaksanakan oleh Tim PkM dilaksanakan dengan cara melibatkan mahasiswa untuk ikut ambil bagian, berbagai kesaksian, mengajar bermain music, dan diakhir kebaktian atau persekutuan biasanya para warga binaan akan makan bersama.

Pembinaan yang dilakukanpun bersifat persuasif yaitu berusaha merubah tingkah laku para warga binaan, memberi teladan, menerima warga binaan apa adanya serta memperlakukan semua warga binaan secara adil di antara sesama mereka sehingga menggugah hatinya untuk melakukan halhal yang terpuji. Pembinaan yang dilakukan secara secara tidak langsung sebenarnya menempatkan warga binaan pemasyarakatan sebagai manusia yang memiliki potensi dan memiliki harga diri dengan hak-hak kewajiban yang sama dengan manusia lainnya.

Tim PkM melakukan pembinaan terencana, terus meneras dan sistematis, baik secara individual maupun kelompok. Harapan penulis melalui pembinaan di dalam lembaga pemasyarakatandi kemudian hari akan berguna untuk menjadi bekal hidup setelah bebas dari lembaga pemsyarakatan.

\section{Model Pembinaan Transformatif}

Pola pembinaan yang dilakukan diintegrasikan dengan berpusat pada Kristus, upaya pembinaan dibawa pada tujuan yang diamanatkan Tuhan (Missio Dei), yaitu supaya warga binaan memiliki relasi secara pribadi dengan Tuhan (to know), warga binaan menjadi murid-murid Yesus (to be), dan warga binaan kelak akan diutus ke dunia menjadi pemimpin yang takut akan Tuhan memiliki hikmat Tuhan (to live). Model pembinaan ini didasari oleh pengajaran Tuhan Yesus yang menerapkan pendekatan holistik, menyadari bahwa trans-formasi baru dapat terjadi secara menyeluruh, berdasarkan transformasi spiritual. Dalam hal ini pengenalan akan Kristus dan memiliki pikiran dan karakter Kristus menjadi dasar dari perubahan pribadi. ${ }^{7}$ Yesus Kristus semasa melakukan pelayanan di dunia memberikan teladan sebagai guru bagi para murid sangat terlibat aktif dan intensif mengarahkan para murid untuk menemukan tujuan Allah. ${ }^{8}$

Spiritual adalah kunci dari seluruh ranah dalam pertumbuhan anak, baik dalam segi kognitif, afektif, psikomotorik, social. Kunci dari pembinaan transformative ini adalah dengan melibatkan pribadi Roh Kudus untuk memperbaharui dan mentransformasi kehidupan warga binaan dari dalam secara spiritual terlebih dahulu. Model Pembinaan ini menekankan keutamaan perubahan dalam manusia batiniah.

${ }^{7}$ Frans Pantan, Purim Marbun, and Syanti D. Mulia, "Model Pembelajaran Berpusat Pada Kristus Untuk Transformasi Bangsa: Studi Deskriptif Di Sekolah Cahaya Cemerlang," SIKIP: Jurnal Pendidikan Agama Kristen 2, no. 1 (February 27, 2021): 26-33, http://sttikat.ac.id/e-journal/index.php/sikip/article/view/76.

${ }^{8}$ Sadrakh Sugiono and Johni Hardori, "Domain Desain Pembelajaran Inkarnatif," Diegesis: Jurnal Teologi 5, no. 2 (August 31, 2020): 14-24, http://sttbi.ac.id/journal/index.php/diegesis/article/view/112. 


\section{SIMPULAN}

Pembinaan transformative pada warga binaan bukan hanya sekedar pelayanan yang terprogram secara rutin untuk mengisi waktu-waktu selama mereka di dalam lembagam tetapi berfokus memberikan makna hidup bagi warga binaan untuk menemukan panggilan dan rencana Allah di dalm dunia. Pembinaan transformative memberikan pencerahan kepada warga binaan bahwa firman Kristus jauh melampaui kebebasan di luar tembok penjara yang memerdekakan manusia menjadi manusia baru di dalam Kristus yang sensitif dengan pribadi Roh Kudus.pembinaan transformative memberikan dorongan baru bagi warga binaanseperti Kristus, mampu memancarkan kebenaran di tengah-tengah dunia yang gagal.

\section{DAFTAR PUSTAKA}

Adiansyah, and Sukihananto. "KEKERASAN FISIK DAN PSIKOLOGIS PADA NARAPIDANA LANSIA DI LEMBAGA PEMASYARAKATAN JAWA BARAT." Jurnal Keperawatan Indonesia 20, no. 3 (2017): 168-175.

Latif, Helen Farida. "Pengaruh Pengajaran Dan Persekutuan Terhadap Tingkat Pertumbuhan Rohani Anak Dan Remaja.” EPIGRAPHE: Jurnal Teologi dan Pelayanan Kristiani 1, no. 1 (2017): 119-138.

Nashriana. Perlindungan Hukum Pidana Bagi Anak Di Indonesia. Jakarta: RajaGrafindo persada, 2012.

Pantan, Frans, Purim Marbun, and Syanti D. Mulia. "Model Pembelajaran Berpusat Pada Kristus Untuk Transformasi Bangsa: Studi Deskriptif Di Sekolah Cahaya Cemerlang." SIKIP: Jurnal Pendidikan Agama Kristen 2, no. 1 (February 27, 2021): 26-33. http://sttikat.ac.id/e-journal/index.php/sikip/article/view/76.

Selvina, Hevi. "Peran Lembaga Pemasyarakatan Dalam Penanggulangan Kekerasan Yang Dilakukan Oleh Narapidana." POENALE 5, no. 2 (2017): 1-10.

Snortum, J, and I Hadar. Criminal Justice : Allies and Adversaries. New York: Palisades Publishers, 1978.

Sugiono, Sadrakh, and Johni Hardori. "Domain Desain Pembelajaran Inkarnatif." Diegesis: Jurnal Teologi 5, no. 2 (August 31, 2020): 14-24.

http://sttbi.ac.id/journal/index.php/diegesis/article/view/112.

Sunaryo, Thomas. "Perpustakaan Penjara." Majalah Bahana. Jakarta, 1983. 